\title{
Pragmatism to the rescue
}

\author{
Henry R. Rollin
}

The expertise of a Cesare Lombroso was not required in order to deduce that the remand prisoner sent to me for examination and report was no Einstein. He was obviously dim, but exactly how dim was part of my job to find out.

To this end I asked him if he minded answering a few simple questions. He nodded his assent. "Are you good at sums?", was my initial query. "Oright", he replied. "Tell me then, what are six times seven?" His close-set eyes narrowed even further as he grappled with the problem. And then enlightenment dawned: "Thirty-nine", he said brightly, "Right?" "No, I'm afraid you're wrong", I replied sorrowfully. "What is it, then?" he demanded, looking somewhat vexed. "Fortytwo", I said. His expression changed to something approaching contempt. "Near enough, innitl", he retorted.

Henry R. Rollin, Emeritus Consultant, Horton Hospital, Epsom

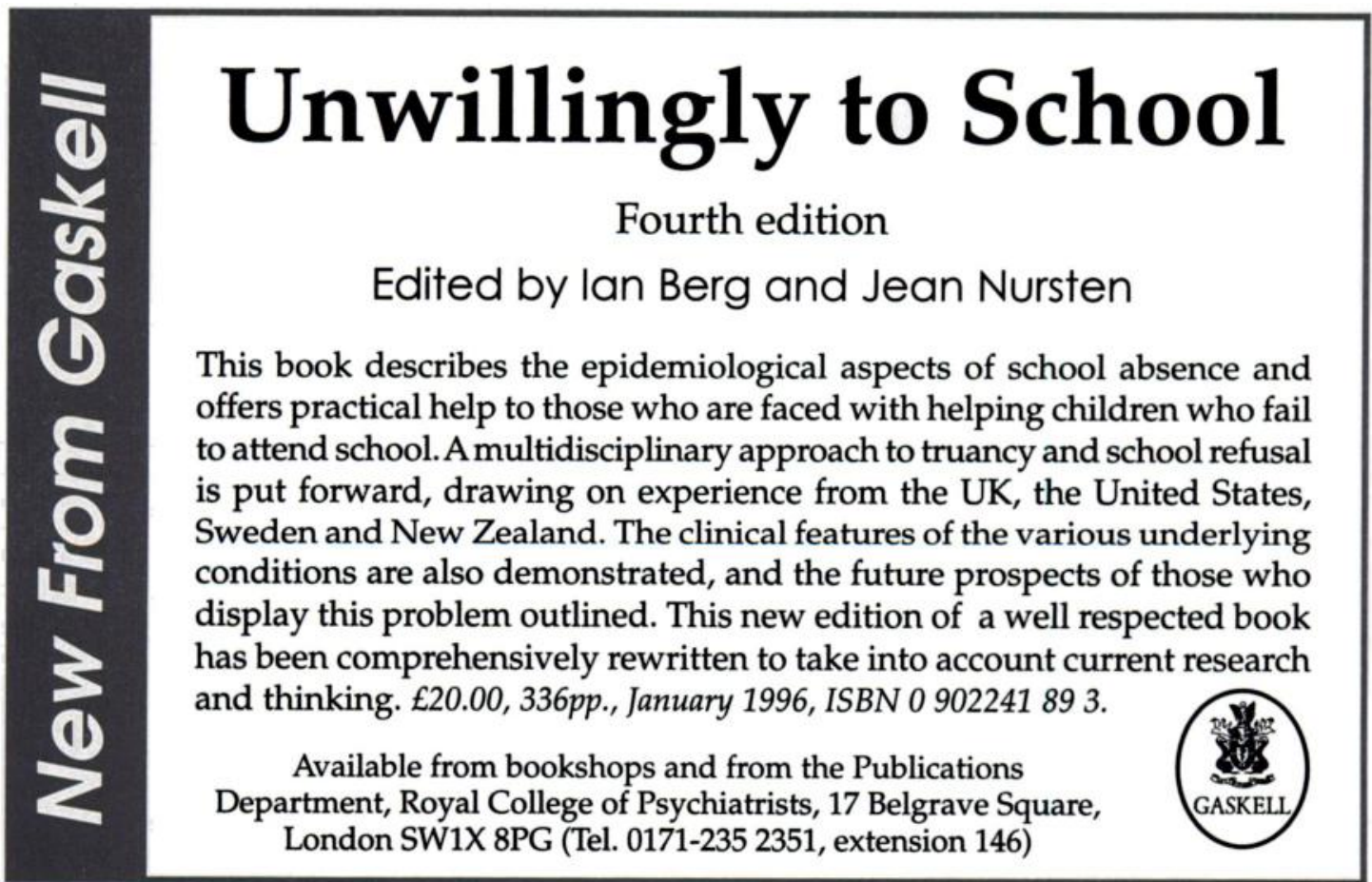

